\title{
Exploiting basic principles to control the selectivity of the vapor phase catalytic oxidative cross-coupling of primary alcohols over nanoporous gold catalysts
}

\author{
Lu-Cun Wang,,$^{\dagger}$ Kara J. Stowers, ${ }^{\dagger}$ Branko Zugic, ${ }^{\dagger}$ Michelle L. Personick, ${ }^{\dagger}$ Monika M. Biener, ${ }^{\perp}$ \\ Juergen Biener, ${ }^{\perp}$ Cynthia M. Friend, ${ }^{*,+,}$ and Robert J. Madix ${ }^{*}$ \\ †Department of Chemistry and Chemical Biology, ${ }^{\star}$ School of Engineering and Applied Sciences, \\ Harvard University, Cambridge, Massachusetts 02138, United States \\ ${ }^{\perp}$ Nanoscale Synthesis and Characterization Laboratory, Lawrence Livermore National \\ Laboratory, Livermore, California 94550, USA
}

\begin{abstract}
Achieving high selectivity for high volume chemical synthesis is important for lowering energy consumption through reduction in waste. We report the selective synthesis of methyl esters methyl acetate and methyl butyrate - through catalytic $\mathrm{O}_{2}$-assisted cross-coupling of methanol with ethanol or 1-butanol using activated, support-free nanoporous gold (npAu). Both wellcontrolled studies on ingots in UHV and experiments under ambient pressure catalytic conditions on both ingots and microspherical hollow shell catalysts reveal guiding principles for controlling selectivity. Under UHV conditions the ester products of the cross-coupling of methanol with both ethanol and 1-butanol evolve near room temperature in temperature programmed reaction studies, indicating that the reactions occur facilely. Under steady-state catalytic operation high, stable activity was observed for cross-coupling in flowing gaseous reactant mixtures at atmospheric pressure and $423 \mathrm{~K}$ with negligible combustion. Optimum selectivity for cross-
\end{abstract}


coupling is obtained in methanol-rich mixtures due to a combination of two factors: (1) the relative coverage of the respective alkoxys, and (2) the relative facility of their $\beta-\mathrm{H}$ elimination. The relative coverage of the alkoxys is governed by van der Waal's interactions between the alkyl groups and the surface; here we demonstrate the importance of these weak interactions in a steady-state catalytic process.

KEYWORDS: nanoporous gold, oxidation, methyl ester synthesis, selectivity, reaction mechanism, heterogeneous catalysis

\section{INTRODUCTION}

Achieving high selectivity for catalytic processes increases energy efficiency and reduces waste in chemical synthesis, which is especially important for high volume chemicals [1-5]. Low molecular weight methyl esters serve as platform chemicals for further synthesis as well as basic elements of various consumer products, and there is potential for substantial improvement in their production. Ideally, methyl esters would be selectively produced above all other products and combustion, in particular, would be suppressed.

Herein, we establish a foundation for understanding and predicting selectivity for $\mathrm{Au}-$ catalyzed methyl ester synthesis that spans a wide range of reaction conditions. Specifically, we demonstrate that the competitive adsorption between methanol and longer-chain alcohols to form their respective alkoxides is key for determining reaction selectivity. The selectivity is directly controlled by the surface coverages of respective alkoxides, which is determined by the composition of alcohols in the gas phase and the surface binding energies of their alkoxides. The binding energies of alcohols to the surface are not factors in this relationship. The dependence of 
this competition on chain length is attributed to the contribution of weak van der Waal's interactions between the alkyl chain and the catalyst surface [6].

Gold-based catalysts have been shown to be effective for selective oxidation of alcohols [3,4,7-14], including the production of methyl esters $[3,4,8,10-12,14,15]$, providing a promising route to sustainable synthesis. Nanoporous $\mathrm{Au}(\mathrm{npAu})$ has been demonstrated to promote selective oxidative coupling of methanol to methyl formate [10], and more recently coupling of ethanol and 1-butanol to ethyl acetate and butyl butyrate, respectively $[11,15]$. These processes use $\mathrm{O}_{2}$ as an oxidant and require relatively mild conditions (1 atm. total pressure, $1 \sim 10 \%$ alcohol, $\left.1 \sim 20 \% \mathrm{O}_{2}, 303 \sim 473 \mathrm{~K}\right)$. Hence, npAu was selected as a catalyst for this detailed investigation of the more complex coupling of methanol with longer-chain alcohols (ethanol or 1-butanol) in order to understand how to enhance and control selectivity for methyl ester production. A new activation procedure [15] that improves the reproducibility of the npAu catalyst performance was key to the studies described herein, because it allows for the systematic investigation of reactivity over vast pressure ranges.
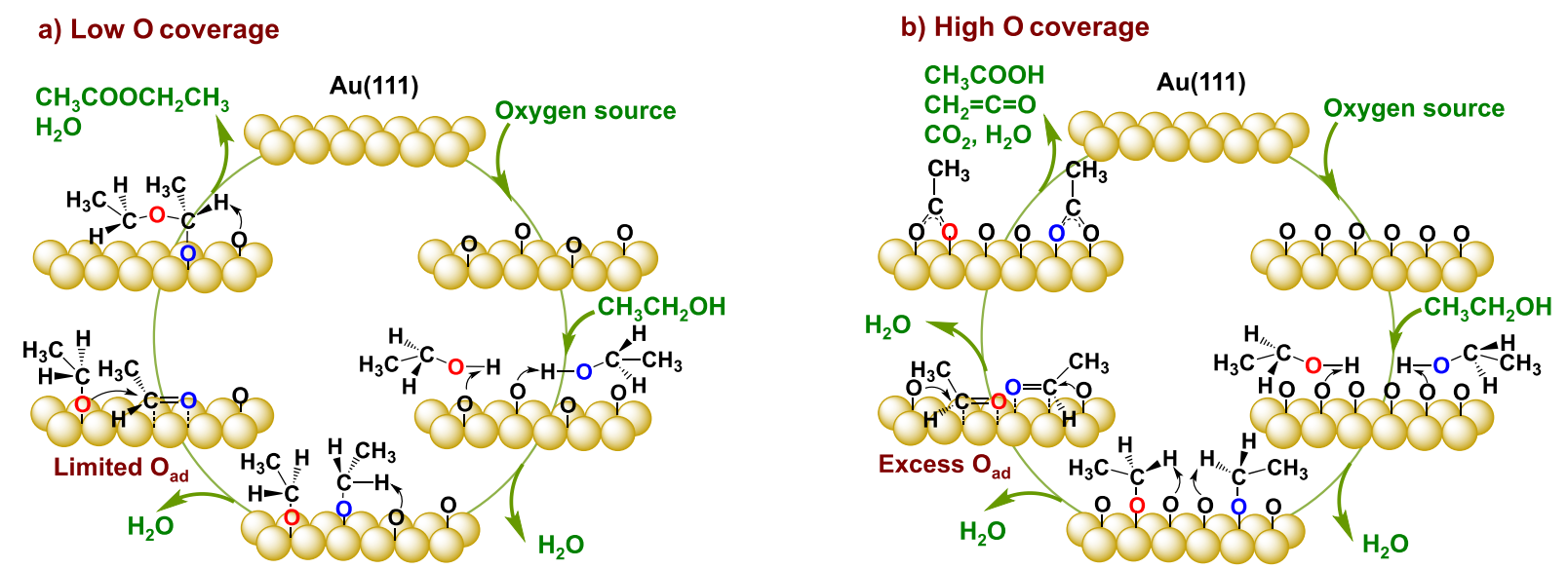

Scheme 1: Reaction pathways for ethanol oxidation at a) low and b) high oxygen coverage as established from ultrahigh vacuum studies on oxygen-covered single-crystal $\mathrm{Au}(111)$ surface [16]. 
The fundamental underpinnings for controlling selectivity for the partial oxidation and oxygen-assisted coupling of mixtures of methanol and other alcohols have been established by mechanistic investigations of $\mathrm{Au}(111)$ [16-18]. All primary alcohols investigated are oxidized through the same general mechanism, which requires atomic oxygen for activation of the alcohols, as illustrated for ethanol oxidation in Scheme 1. Key to this reaction is the activation of the $\mathrm{O}-\mathrm{H}$ bond in the alcohol by adsorbed atomic oxygen to form the adsorbed alkoxy intermediate and the subsequent $\beta-\mathrm{C}-\mathrm{H}$ bond activation in the alkoxy to yield the aldehyde, which reacts further with the adsorbed alkoxy. The selectivity for oxidation of a pure alcohol, such as ethanol, thus depends on the initial coverage of atomic oxygen and on the chain length of the alcohol. Specifically, selective oxidation is favored over combustion at low oxygen coverage [17-19]; at constant oxygen coverage the amount of aldehyde formed increases with the length of the alkyl chain due to greater ease of $\beta-\mathrm{C}-\mathrm{H}$ bond activation $[16,20]$. This general mechanism for oxidative coupling of alcohols, has been demonstrated to be operative under operating catalytic conditions for npAu catalysts [10,11], as well as on single-crystal Au surfaces.

The more complex process of cross-coupling methanol with other primary alcohols also has been demonstrated to occur readily on $\mathrm{O} / \mathrm{Au}(111)[16,20]$. In such a case, the reactant alcohols both react with adsorbed $\mathrm{O}$ in a competitive fashion. Cross-coupling then occurs via reaction of one alkoxy with the aldehyde produced by the other. Optimum selectivity for crosscoupling requires that the relative concentrations of the dissimilar adsorbed alkoxy species be controlled. Thus, the competition between the reactant alcohols for reactive sites on the gold is a critical factor; the number of active sites being determined by adsorbed $\mathrm{O}$.

Using Au single crystals, it was demonstrated that the relative population of the different alkoxy species on the surface is determined by their alkyl chain lengths-longer-chain alkoxides 
compete more effectively for active sites. The underlying reason for this is a pre-equilibrium that determines the relative concentration of the alkoxides, illustrated for methanol and ethanol in Scheme 2. The preference for binding of longer chain alkoxides on gold is attributed to stronger interactions of the alkyl group with the surface via van der Waal's forces based on theoretical studies [6].

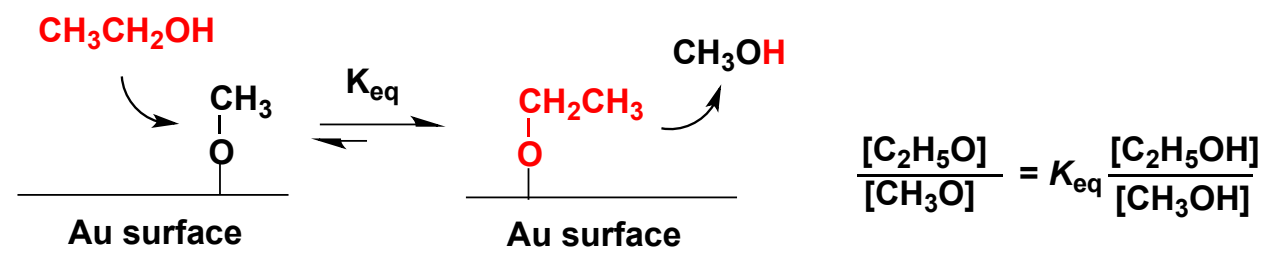

Scheme 2 The adsorption pre-equilibrium between methanol and ethanol determined from UHV studies on single-crystal $\mathrm{Au}(111)$ surface [16].

In this paper we test these principles for a functional catalytic material, $\mathrm{npAu}$, under a wide range of reaction conditions, spanning ultrahigh vacuum to atmospheric pressure. We establish that the same reaction mechanism applies on npAu and Au single crystals; thus, the selectivity for production of the methyl esters is controlled by the same factors under working catalytic conditions as in the model studies, including the competition for sites between the reactant species on the more complex catalytic material. This further establishes the predictive value of fundamental investigations for catalytic processes and specifically demonstrates the importance of van der Waal's interactions in determining selectivity.

Catalyst Materials. Two different forms of npAu were investigated in this work-ingots $(\sim 5$ mm diameter; 200-300 $\mu \mathrm{m}$ thick, BET surface area $\left.4.6 \mathrm{~m}^{2} \mathrm{~g}^{-1}\right)$ and spherical hollow shells $(\sim 8$ $\mu \mathrm{m}$ diameter; $\sim 400 \mathrm{~nm}$ thick shell, BET surface area $7.2 \mathrm{~m}^{2} \mathrm{~g}^{-1}$ ). The synthesis of these materials 
is described in detail elsewhere $[10,11,15]$. The bulk $\mathrm{Ag}$ content of these materials is $\sim 3 \%$ and $\sim 1.5 \%$ for the ingots and shells, respectively, determined using EDS. The surface silver concentration on the ingot and shells was measured to be 10 at. $\%$ and 6 at. $\%$, respectively, using XPS. The as-prepared ingots and shells have average ligament diameters of $50 \pm 10 \mathrm{~nm}$ and $80 \pm$ $20 \mathrm{~nm}$ and average pore sizes of $50 \pm 20$ and $80 \pm 20 \mathrm{~nm}$ respectively, determined from analysis of SEM images (Fig. S1 and Table S4).

All catalyst materials were subjected to an activation process that yields reproducible and sustained activity of both the npAu ingots and shells, described elsewhere [15]. Briefly, the catalyst materials were activated under a flow of $30 \mathrm{~g} / \mathrm{Nm}^{3}$ of ozone in a $50 \% \mathrm{O}_{2} / \mathrm{He}$ gas mixture at a total flow rate of $50 \mathrm{~mL} / \mathrm{min}$ at $423 \mathrm{~K}$ in a flow reactor for $\sim 1$ hour. This procedure does not lead to any significant changes in the ligament size or structure. This procedure yields a very stable and reproducibly active material. After reaction in the flow reactor, the three-dimensional network morphology was largely maintained but the ligament size for both ingots and shells increases up to ca. 100 250 $\mathrm{nm}$ and the surface area decreases to $\sim 3 \mathrm{~m}^{2} / \mathrm{g}$ for the ingots and $\sim 0.7$ $\mathrm{m}^{2} / \mathrm{g}$ for the shells.

Ultrahigh vacuum experiments. All ultrahigh vacuum (UHV) experiments were performed on npAu ingot samples in a chamber with a base pressure $<5 \times 10^{-10}$ Torr. The npAu sample was cleaned using ozone treatment, described elsewhere [21]. Subsequent to cleaning, the npAu was active for dissociation of $\mathrm{O}_{2}$ [21]. Controlled exposure of the npAu to $\mathrm{O}_{2}$ at $300 \mathrm{~K}$ was used to produce a coverage of atomic oxygen of $10 \pm 2 \%$ of saturation coverage using an established procedure $[21,22]$.

Reactant alcohols, mixtures of methanol and either ethanol or 1-butanol, were prepared as 
liquid mixtures with different relative concentration of the two alcohols. The mole fraction of methanol was varied between 0-100 \% and determined by condensing the mixture on clean $\mathrm{npAu}$, which is not reactive, at low temperature $(130-150 \mathrm{~K})$. Temperature programmed desorption was used to quantify the relative concentrations of the two alcohols dosed onto the surface, similar to the procedure used for single crystals [16]. The alcohol mixtures were introduced to the npAu ingot using a directed doser with an enhancement factor of $\sim 50$ [23]; the doses cited are based on the background pressure rise during gas introduction and corrected for this enhancement and are stated in Langmuir $\left(1 \mathrm{~L}=10^{-6}\right.$ torr sec).

Reactivity studies were performed by first adsorbing atomic $\mathrm{O}$ at $300 \mathrm{~K}$, cooling to 130 $\mathrm{K}$, exposure to the alcohol mixtures and subsequent temperature programmed reaction. The oxygen coverage was controlled by adjusting the time of exposure of $\mathrm{O}_{2}$ based on a calibration curve (Fig. S2). Temperature programmed reaction experiments were conducted according to well-established protocols [24]. The heating rate for all experiments was nearly constant at $3 \mathrm{~K} \mathrm{~s}^{-}$

1. Reaction products were identified by quantitative mass spectrometry (Hiden HAL/3F) using fragmentation patterns obtained from authentic samples (Supporting Information).

\section{Catalytic experiments in flow reactors.}

The catalytic experiments were performed in a conventional fixed-bed microreactor using both the npAu ingot samples and the npAu shells. The catalysts were cooled to $323 \mathrm{~K}$ after activation by ozone treatment and then ramped from 323 to $423 \mathrm{~K}(10 \mathrm{~K} / \mathrm{min})$ in a flow of $10 \%$ methanol and $20 \% \mathrm{O}_{2}$ in $\mathrm{He}(50 \mathrm{~mL} / \mathrm{min})$. The activity of the npAu catalysts for the selfcoupling of methanol was allowed to stabilize ( 12 hours) before the cross-coupling experiments were begun. All experiments were conducted at a total flow rate of $50 \mathrm{~mL} / \mathrm{min}$ and a temperature 
of $423 \mathrm{~K}$ unless otherwise stated. For the experiments with ingots the concentration of different alcohols in the reaction mixture was adjusted via their vapor pressure, by guiding the saturated He gas stream (at around $22{ }^{\circ} \mathrm{C}$ ) through a coiled condenser. The vapor pressure at different temperatures was calculated using the KDB database (Korea Thermophysical Database). In the case of the npAu shells, the alcohols were introduced via syringe pump injection into a heated line on the reactor, and the relative gas phase compositions of the different alcohols were adjusted by varying the composition of the liquid alcohol mixture in the syringe, taking into account the different vapor pressures when calculating the ratio of alcohols and the injection rate.

The stream of gases at the exit of the reactor was monitored online by a gas chromatograph (Agilent 7890A series, Column HP-Plot/Q and GS-CARBONPLOT) coupled with a mass spectrometer (Agilent 5975C series, inert MSD with triple-axis detector). No reactions were detected in the absence of the npAu catalyst under the conditions studied in the present work. Nor were products observed in the absence of dioxygen in the reactant mixture. More details about the data analysis including the derivation of conversion and selectivity can be found in the Supporting Information.

\section{RESULTS}

Reactivity of npAu ingots in ultrahigh vacuum. Selective oxidation of a mixture of methanol and either ethanol or 1-butanol, including production of the methyl esters, is promoted on npAu precovered with adsorbed atomic $\mathrm{O}$ (0.1 saturation coverage) under ultrahigh vacuum conditions; no reaction occurs on clean npAu. Adsorbed atomic oxygen was formed via exposure of $\mathrm{O}_{2}$ ( $\mathrm{p}=10^{-9}$ torr) to the catalyst at $300 \mathrm{~K}[21,25]$. The alcohol mixtures were dosed such that there is a slight excess of the alcohols. Under these conditions, there was no residual oxygen detected in 
temperature programmed desorption; atomic $\mathrm{O}$ recombines above $500 \mathrm{~K}$ to yield $\mathrm{O}_{2}$, and none was observed.

A complex mixture of products form during temperature programmed reaction with the product distribution depending upon the ratio of the alcohols. The products formed from reaction of methanol with ethanol are methyl formate, ethyl acetate, methyl acetate, $\mathrm{CO}_{2}, \mathrm{H}_{2} \mathrm{O}$ and $\mathrm{H}_{2}$, and perhaps a trace of acetaldehyde (near $300 \mathrm{~K}$ ), as illustrated for a 85:15 mixture of $\mathrm{CH}_{3} \mathrm{OH}$ and $\mathrm{C}_{2} \mathrm{H}_{5} \mathrm{OH}$ (Fig. 1a). No ethyl formate was detected for any mixture studied. The onset of reaction is below $300 \mathrm{~K}$, based on the evolution of water and $\mathrm{H}_{2}$ commencing at 180 and $210 \mathrm{~K}$, respectively (Fig. 1). All three ester products evolve at $\sim 300 \mathrm{~K}$ (Fig. 1a). In the case shown, the esters account for $90 \%$ of the product yield; the yields of the various esters formed are $53 \%$ methyl acetate, $29 \%$ ethyl acetate, and $8 \%$ methyl formate. Under these conditions, $\mathrm{CO}_{2}$ accounts for only $10 \%$ of the products.

An analogous set of products was formed during temperature-programmed reaction of mixture of methanol (0.85) and 1-butanol (0.15) on $\mathrm{O} / \mathrm{npAu}(\mathrm{O} \sim 0.08$ saturation coverage) (Fig. 1b). The esters - methyl butyrate, butyl butyrate, and methyl formate - are produced at $345 \mathrm{~K}$, $385 \mathrm{~K}$ and $290 \mathrm{~K}$, respectively. Butyraldehyde is also formed in a broad peak between 320-370 $\mathrm{K} ; \mathrm{H}_{2}, \mathrm{H}_{2} \mathrm{O}$, and $\mathrm{CO}_{2}$ are the other products (Fig. 1b). The product distribution is significantly different than for the ethanol case, however. In particular, the overall yields of the esters is lower, accounting for only $\sim 28 \%$ of the products, compared to $90 \%$ ester production from the methanol/ethanol mixture at the comparable composition. Furthermore, butyl butyrate only accounts for $\sim 1 \%$ compared to $29 \%$ for the analogous product from ethanol, ethyl acetate. Methyl butyrate and methyl formate are formed in a ratio of 2.9:1, total accounting for $27 \%$ of the products. The other major differences for the reactions of 1-butanol is that the aldehyde, 
butyraldehyde, accounts for $24 \%$ of the product yield with $\mathrm{CO}_{2}$ produced in $49 \%$ yield. For both ethanol and 1-butanol the simultaneous formation of $\mathrm{CO}_{2}$ and $\mathrm{H}_{2}$ near $400 \mathrm{~K}$ is typical of formate decomposition on silver surfaces [26,27].
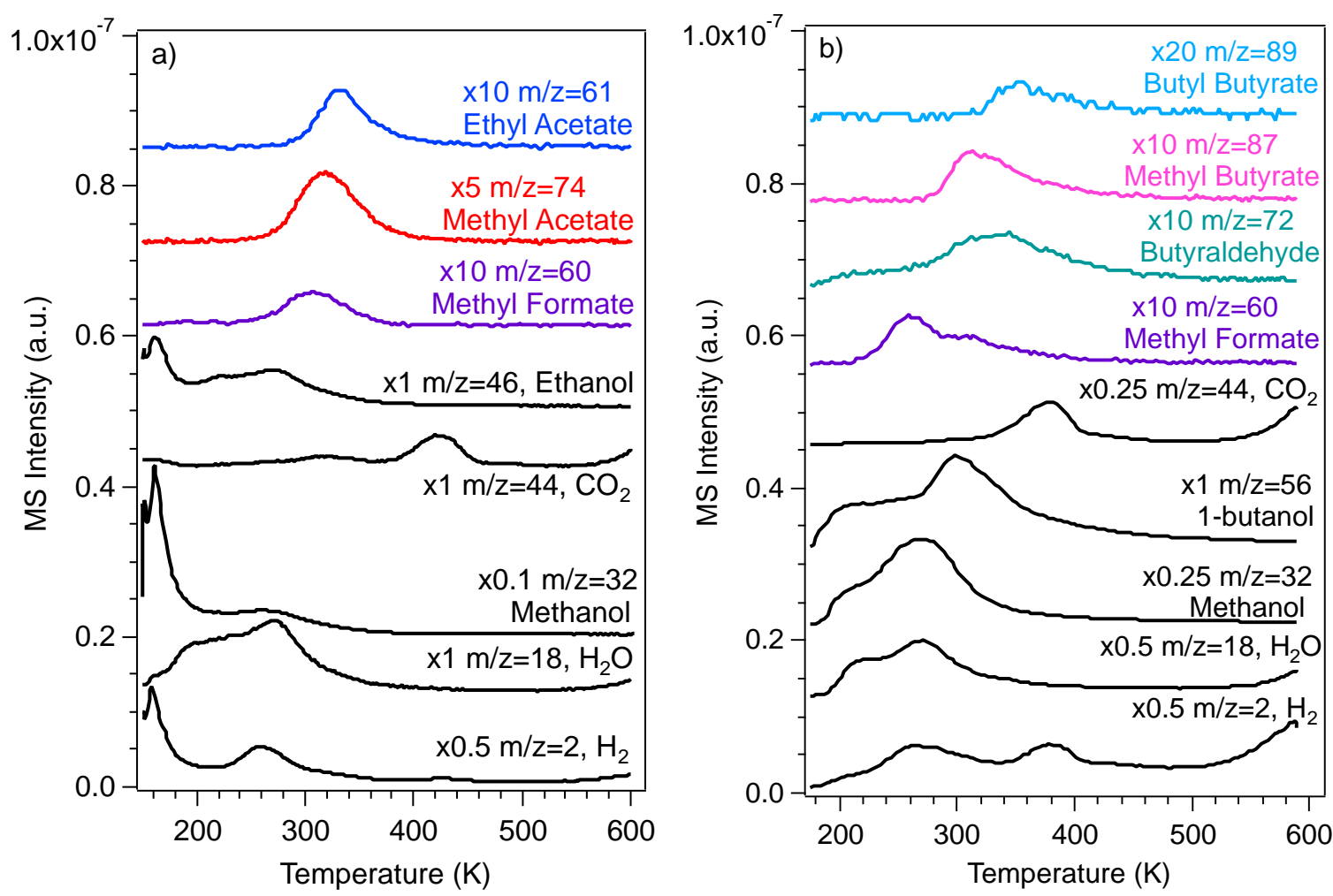

Fig. 1. Temperature programmed reaction spectra for mixtures of methanol $(85 \%)$ and a) ethanol and b) 1butanol exposed to npAu pre-covered with atomic $\mathrm{O}$ at $180 \mathrm{~K}$. The initial atomic oxygen, created by exposure of the npAu to $\mathrm{O}_{2}\left(10^{-9}\right.$ torr) at $300 \mathrm{~K}$, was dosed at $10 \%$ of the calibrated saturation coverage (Fig. S2). The coverage for ethanol/methanol required a $6 \mathrm{~L}$ dose and for 1-butanol/methanol a $4 \mathrm{~L}$ dose. Alcohol mixtures were introduced $(1 \mathrm{~L})$ at $180 \mathrm{~K}$. The composition of alcohol mixtures reported was calculated on a molar basis. Overlapping mass fragments have been subtracted in the data shown for clarity. Procedures for correcting for fragmentation are described in the Supporting Information. The heating rate was approximately $3 \mathrm{~K} \mathrm{~s}^{-1}$.

The product distribution for oxidation of the alcohol mixtures over the $\mathrm{O} / \mathrm{npAu}$ ingot strongly depends on the methanol mole fraction in the two mixtures (Fig. 2). A significant excess of methanol ( $\sim 9.9$ mole fraction) is required to achieve optimum selectivity for formation of the methyl ester for cross-coupling with ethanol (Fig. 2). At low methanol mole fractions, selfcoupling of ethanol dominates reactivity. Roughly equal amounts of methyl acetate and ethyl 
acetate form at a methanol mole fraction of 0.6. Methyl acetate becomes the predominant product at a methanol mole fraction of 0.9 although non-negligible amounts of the self-coupled methanol product, methyl formate, also form at this methanol mole fraction.

The key conclusions of these investigations on npAu ingots under ultrahigh vacuum conditions are that (1) atomically adsorbed oxygen is required for initiation of these selective oxidation processes and (2) the variation in product distribution is similar to those measured on O-covered $\mathrm{Au}(111)[16]$.

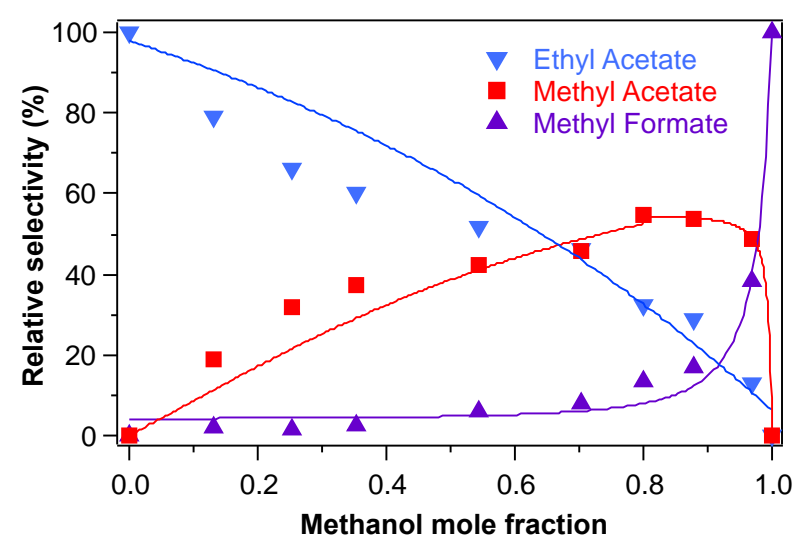

Fig. 2. Relative selectivity of different esters formed via self-coupling and cross-coupling (methyl formate, ethyl acetate, and methyl acetate, with no detectable ethyl formate) in the methanol-ethanol reaction under UHV conditions as a function of methanol mole fraction. Each point represents a TPRS experiment for methanol and ethanol cross-coupling. Dioxygen was dosed at $300 \mathrm{~K}$ to achieve $10 \%$ saturation and then cooled to $180 \mathrm{~K}$ where alcohol mixtures with the specified methanol mole fraction was dosed for $2 \mathrm{~L}$. No aldehyde was detected.

\section{Steady-state catalytic studies of npAu at atmospheric pressure}

Selective oxidation of binary gaseous mixtures of methanol/ethanol or methanol/1butanol at atmospheric pressure using npAu catalysts and $\mathrm{O}_{2}$ as an oxidant also yields a complex mixture of products, including the methyl esters. The products formed from the methanol/ethanol reaction are acetaldehyde, methyl acetate, ethyl acetate and methyl formate as shown for a 0.7:0.3 mixture of methanol and ethanol (Fig. 3a; Fig. S3). Ethyl formate may also be formed 
when ethanol is in excess (Fig. S4). The products of the methanol/1-butanol reaction are butyraldehyde, methyl butyrate, butyl butyrate, and methyl formate as illustrated for a 0.7:0.3 mixture of methanol/1-butanol (Fig. 3b; see also Fig. S5). No butyl formate, $\mathrm{CO}_{2}$, organic acids, or formaldehyde was detected in any of the experiments. The activity of the catalysts is stable over many hours of operation at $423 \mathrm{~K}$ as illustrated for a npAu ingot (Fig. 3).
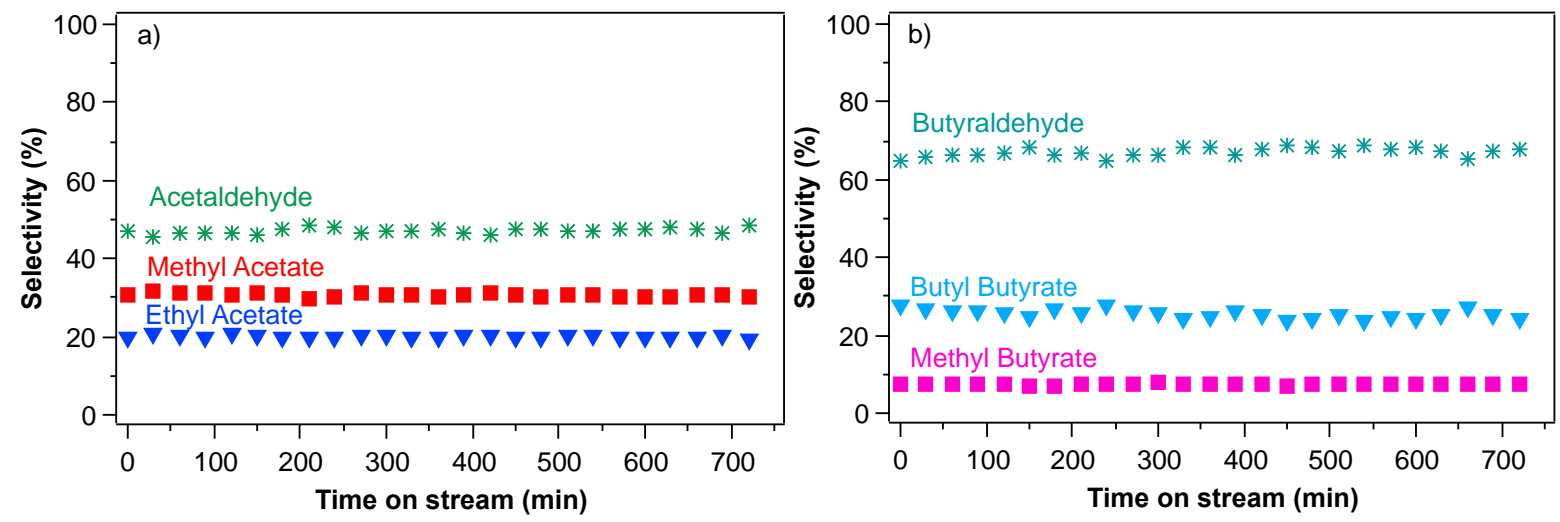

Fig. 3. The selectivity of npAu ingot as a function of time on stream in oxidative coupling of methanol with a) ethanol, reaction conditions: 20 vol. $\% \mathrm{O}_{2}, 4.8$ vol.\% methanol, 2.1 vol. $\%$ ethanol, $423 \mathrm{~K}, 50 \mathrm{~mL} / \mathrm{min}$. The conversion of methanol and ethanol was $2.8 \%$ and $13.3 \%$, respectively; and b) 1-butanol, reaction conditions: 20 vol.\% $\mathrm{O}_{2}, 2.8 \mathrm{vol} \%$ methanol, $1.2 \mathrm{vol} . \%$ 1-butanol, $423 \mathrm{~K}, 50 \mathrm{~mL} / \mathrm{min}$. The conversion of methanol and 1butanol was $1.0 \%$ and $18.1 \%$, respectively. No significant amount of methyl formate was observed in either case.

The behavior of the npAu ingots and hollow shells is very similar. Both samples have comparable mass-specific reaction rates (Table 1). However, the surface-area-specific reaction rate for the npAu hollow shells exceeds that of the ingot sample by a factor of $\sim 5$. We attribute this difference to moderate pore diffusion limitations in the case of the ingots [28]; no such limitations are expected for the thin hollow shells despite the relatively high ethanol conversion, i.e., $21 \%$. The estimated TOF of ethanol conversion based on the total surface area of the npAu shells $\left(0.28 \mathrm{~s}^{-1}\right)$ is comparable to that reported for ethanol oxidation on a $\mathrm{Au} / \mathrm{SiO}_{2}$ catalyst $\left(0.36 \mathrm{~s}^{-}\right.$ ${ }^{1}$ at $200{ }^{\circ} \mathrm{C}, \mathrm{Au}$ particle size $15 \mathrm{~nm}$ ) [29]. However, it is believed that only surface silver activates 
$\mathrm{O}_{2}$. Based on the surface concentration of silver, the TOF number would be approximately $5 \mathrm{~s}^{-1}$. Nevertheless, the dependence of the product distributions on methanol mole fraction is essentially the same for similar reaction conditions (see Figs. 4, 5, S6, and S7).

Table 1 Comparison of the catalytic activity of npAu ingots and shells in the cross-coupling of methanol and ethanol $^{a}$

\begin{tabular}{|c|c|c|}
\hline npAu sample & Ingot & Shells \\
\hline Ethanol conversion (\%) & 18.2 & 21.0 \\
\hline Mass-specific reaction rate $\left(10^{-6} \mathrm{~mol} \mathrm{~s}^{-1} \mathrm{~g}_{\text {cat }}^{-1}\right)$ & 3.8 & 4.5 \\
\hline Surface-area-specific reaction rate $\left(10^{-6} \mathrm{~mol} \mathrm{~s}^{-1} \mathrm{~m}^{-2}\right)$ & 1.3 & 6.4 \\
\hline Turnover frequency $\left(\mathrm{TOF}, \mathrm{s}^{-1}\right)^{b}$ & $0.056\left(0.5^{c}\right)$ & $0.28\left(5^{c}\right)$ \\
\hline
\end{tabular}

${ }^{a}$ Reaction conditions: $423 \mathrm{~K}$, methanol mole fraction $0.7,20 \mathrm{vol} . \% \mathrm{O}_{2}, 50 \mathrm{~mL} / \mathrm{min} .{ }^{b}$ calculated assuming an exposed metal site density of $1.4 \times 10^{19}$ atoms $\mathrm{m}^{-2} .{ }^{c}$ calculated based on surface silver concentration of 10 at. $\%$ and 6 at. $\%$ for the ingot and shells, respectively.

The product distributions strongly depend on the ratio of methanol to the longer-chain alcohol in a pattern quite similar to those measured on the npAu ingot in ultrahigh vacuum (Figs. 2,4 , and 5). At the low methanol mole fraction $(<0.20)$, production of the respective aldehydeacetaldehyde from ethanol or butyraldehyde from 1-butanol—is predominant accounting for $\sim 60 \%$ and $80 \%$ of the products. Ester formation is observed at higher methanol fraction with the selectivity increasing monotonically for both the methanol/ethanol and methanol/1-butanol mixtures (Figs. 4 and 5). Concomitantly, aldehyde production falls. The selectivity for formation of the methyl esters (methyl acetate and methyl butyrate) is a maximum for a methanol mole fraction of $\sim 0.9$ for methyl acetate and 0.95 for methyl butyrate - the former being essentially the same mole ratio required for optimal selectivity for methyl ester formation under ultrahigh vacuum conditions on the npAu (Fig. 2). At a methanol mole fraction near 0.9, the production 
of methyl formate sharply increases and aldehyde production falls for both cases. Comparable results were obtained with the npAu shell samples (423 K, see Figs. S6 and S7). Note that the conversion of ethanol and 1-butanol also changes with the methanol mole fraction. With a fixed total concentration of alcohols, higher conversions of both ethanol and 1-butanol were observed at larger methanol fractions.
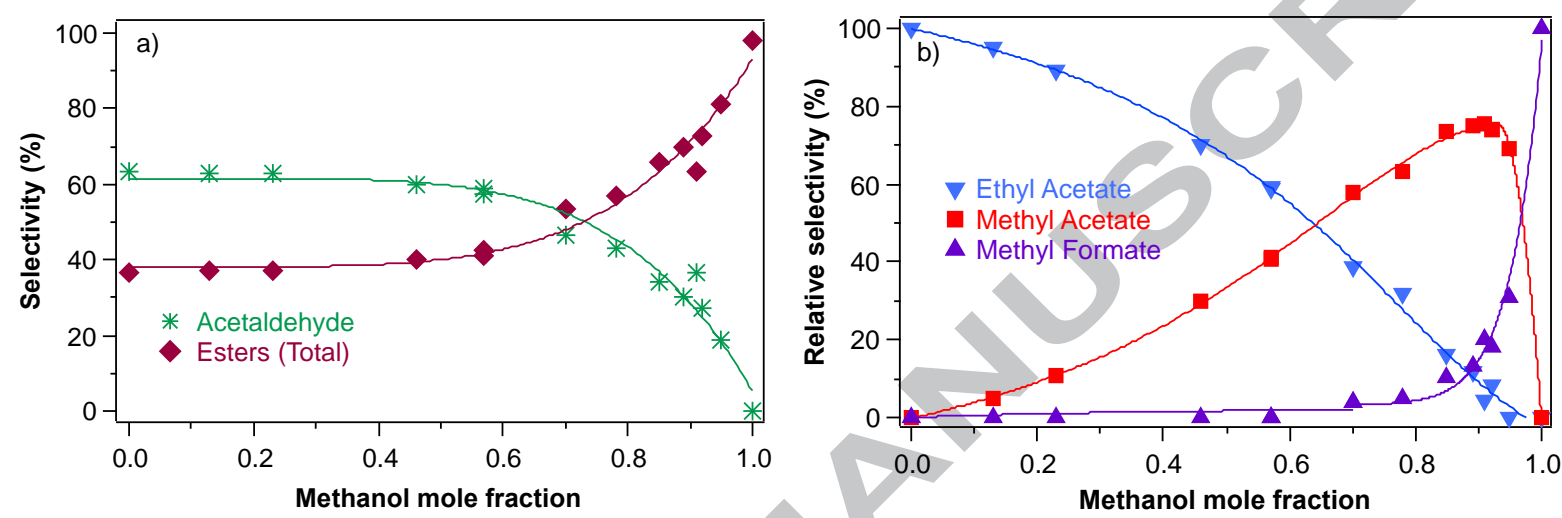

Fig. 4. Variation in selectivity as a function of methanol mole fraction for selective oxidation of various mixtures of methanol and ethanol over a npAu ingot catalyst using $\mathrm{O}_{2}$ as an oxidant. a) The selectivity for formation of the products: acetaldehyde and esters (the sum of methyl formate, methyl acetate and ethyl acetate), no detectable amount of formaldehyde, acids or $\mathrm{CO}_{2}$ formation. b) Relative selectivity for production of the various estersmethyl formate, ethyl acetate, and methyl acetate. Reaction conditions: fixed-bed microreactor, $35 \mathrm{mg} \mathrm{npAu}$ ingot sample, 20 vol. $\% \mathrm{O}_{2}, 5 \sim 6$ vol.\% alcohols in total, $423 \mathrm{~K}, 50 \mathrm{~mL} / \mathrm{min}$.
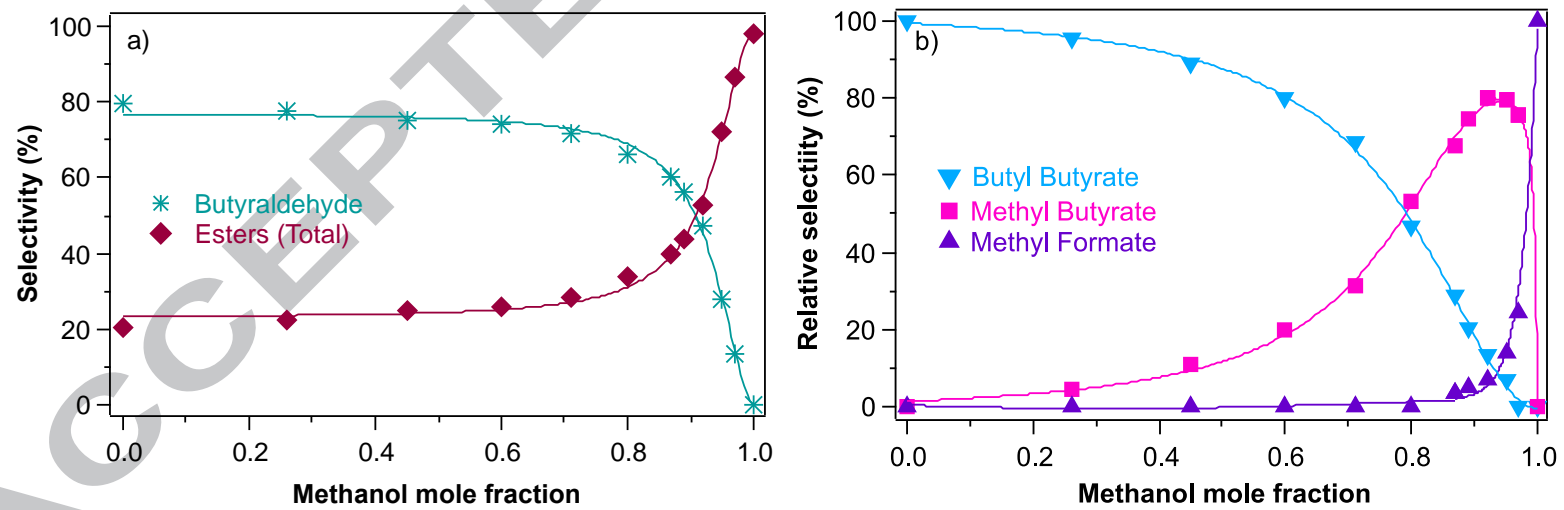

Fig. 5. Variation in selectivity as a function of methanol mole fraction for selective oxidation of various mixtures of methanol and 1-butanol over a npAu catalyst using $\mathrm{O}_{2}$ as an oxidant. a) The selectivity for formation of the products: butyraldehyde and esters (the sum of methyl formate, methyl butyrate, and butyl butyrate), no detectable amount of formaldehyde, acids or $\mathrm{CO}_{2}$ formation. b) Relative selectivity for production of the various esters - methyl formate, butyl butyrate, and methyl butyrate, no detectable amount of butyl formate) in methanol-butanol reaction as a function of methanol molar fraction. Reaction conditions: fixed-bed microreactor, $35 \mathrm{mg}$ npAu ingot sample, 20 vol. $\% \mathrm{O}_{2}, 3 \sim 6$ vol. \% alcohols in total, $423 \mathrm{~K}, 50 \mathrm{~mL} / \mathrm{min}$. 
Reaction selectivity is relatively insensitive to variation in $\mathrm{O}_{2}$ concentration for both the methanol/ethanol and methanol/1-butanol reactions (Fig. 6). Data were obtained for a methanol mole fraction, $\chi$, of 0.7 , where acetaldehyde (butyraldehyde), methyl acetate (methyl butyrate) and ethyl acetate (butyl butyrate) are all significant products (Figs. 4 and 5). The conversion of 1-butanol was constant at $20 \%$ for $\mathrm{O}_{2}$ concentrations above 5 vol. $\%$; between 3 vol. $\%$ and 1 vol. $\%$ it decreased to $10 \%$ (Fig. S8b). These results indicate near saturation of the sites available for oxygen binding at oxygen partial pressures above 3 vol.\% oxygen in the reactant mixtures. In addition, the selectivity of various products is only weakly affected even when the activity is limited by oxygen supply at very low $\mathrm{O}_{2}$ concentrations.
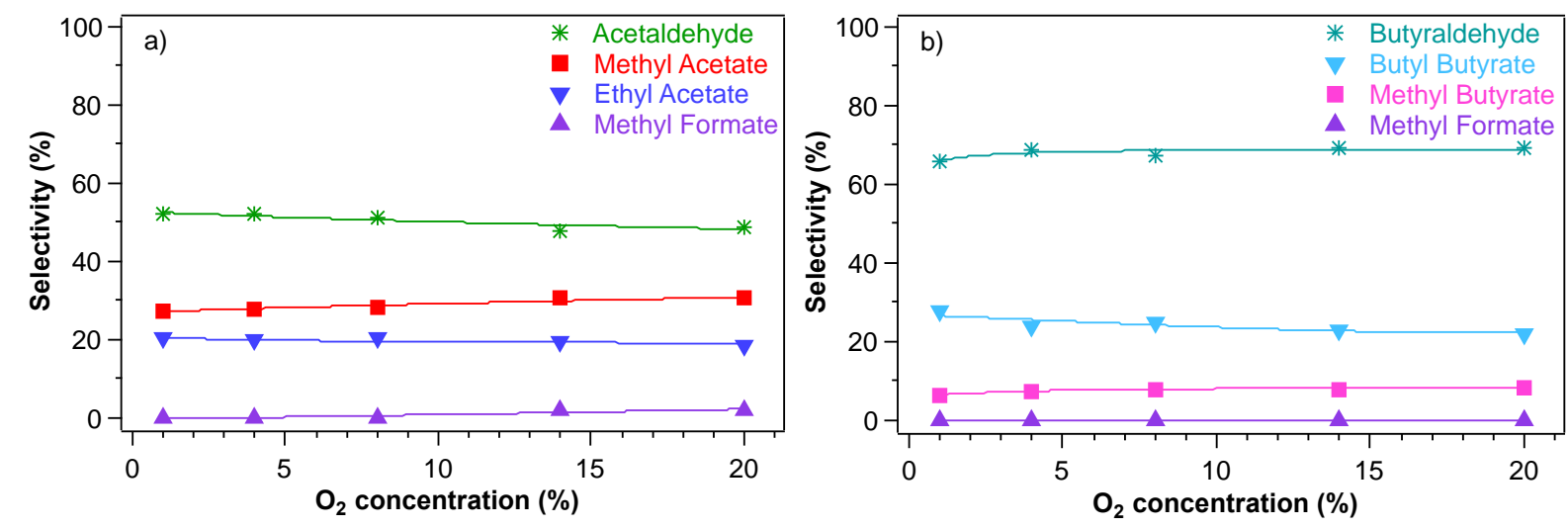

Fig. 6. Steady-state selectivity as a function of oxygen concentration for the cross coupling of a) methanolethanol, reaction conditions: $423 \mathrm{~K}, 50 \mathrm{~mL} / \mathrm{min}, 4.8 \%$ methanol, $2.1 \%$ ethanol $\left(\chi_{\text {methanol }}=0.7\right)$ and b) methanolbutanol, reaction conditions: $423 \mathrm{~K}, 50 \mathrm{~mL} / \mathrm{min}, 2.8 \%$ methanol, $1.2 \%$ 1-butanol $\left(\chi_{\text {methanol }}=0.7\right)$.

The dependence of the selectivities and conversion on total alcohol concentration was also studied. The conversion of ethanol decreases from $28 \%$ to $11 \%$ as the total alcohol concentration (methanol + ethanol) is increased from $1 \%$ to $13 \%$ (Fig. S9a). Similarly, the conversion of 1-butanol decreases from $30 \%$ to $15 \%$ as the total alcohol percentages increases from $1 \%$ to $12 \%$ (Fig. S9b). The steady decline in alcohol conversion can be attributed to a lack 
of sufficient adsorbed oxygen for activation of the alcohols, in agreement with the requirements of the catalytic cycle (Scheme 1). Over this same range of total alcohol concentrations, there is a decrease in aldehyde formation and a corresponding increase in the production of methyl acetate and ethyl acetate or methyl butyrate and butyl butyrate (Fig. 7). These changes are also consistent with the mechanism (Scheme 1); as the alcohol concentration is lowered, the surface concentration of alkoxy species decreases, and the kinetically first order hydrogen elimination from the alkoxy to yield the aldehyde (followed by its rapid desorption) becomes more favored over the second order reactions among the alkoxy species necessary to yield the esters.
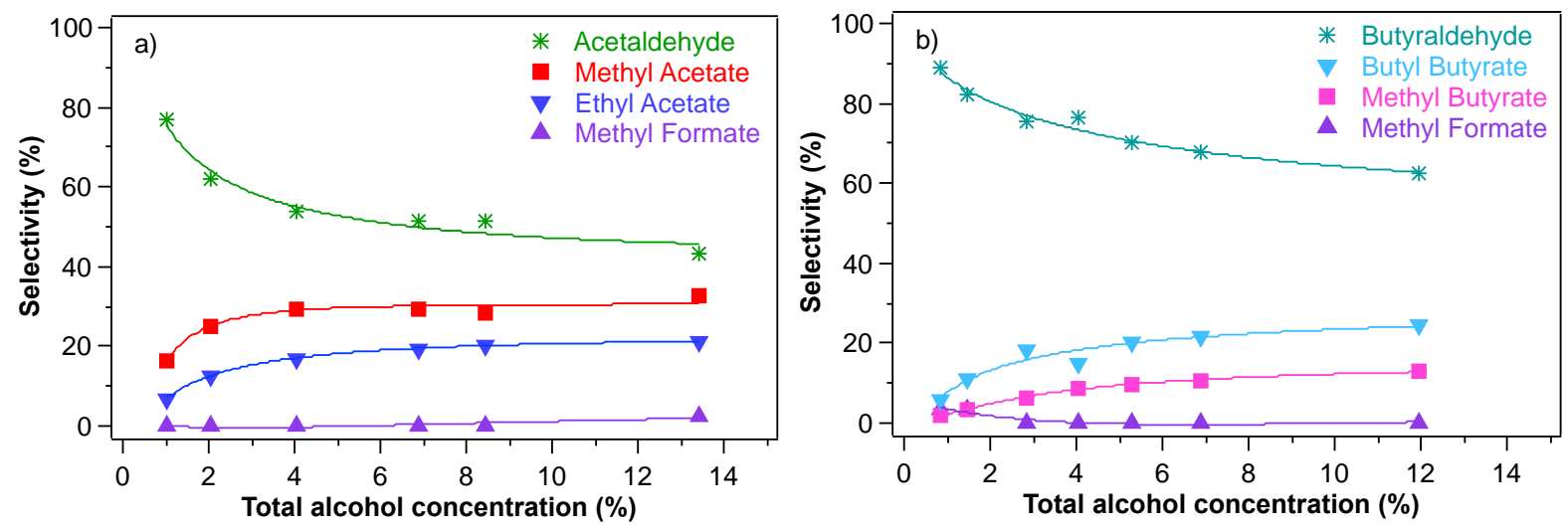

Fig. 7. Steady-state selectivity as a function of total alcohol concentration for the cross coupling of a) methanolethanol, reaction conditions: $423 \mathrm{~K}, 50 \mathrm{~mL} / \mathrm{min}, 20 \% \mathrm{O}_{2}, \chi_{\text {methanol }}=0.7$ and b) methanol-butanol, reaction conditions: $423 \mathrm{~K}, 50 \mathrm{~mL} / \mathrm{min}, 20 \% \mathrm{O}_{2}, \chi_{\text {methanol }}=0.7$.

\section{DISCUSSION}

The TPRS measurements (Fig. 1) reveal a strong influence of silver at the surface. As noted previously, dioxygen is not activated by extended gold surfaces, and its activation has been attributed to the presence of silver at the surface of the npAu [30-33]. The desorption of molecularly chemisorbed oxygen and the recombinative desorption of oxygen adatoms occur on this surface, analogous to the behavior seen on single crystal silver surfaces $[34,35]$. However, 
the temperature at which these events occur on the npAu are indicative of the effects of metal alloying [36]. The data strongly suggest that adsorbed atomic oxygen is formed via dissociation of a chemisorbed molecular oxygen state associated with silver or modified silver sites at the surface.

Further, as noted in Results, the evolution of $\mathrm{CO}_{2}$ and $\mathrm{H}_{2}$ near $400 \mathrm{~K}$ resulting from the coadsorption of methanol and ethanol on $\mathrm{O} / \mathrm{npAu}$ is characteristic of formate decomposition on $\mathrm{Ag}$, not $\mathrm{Au}$, surfaces [19,27,37]; in fact, the evolution of $\mathrm{H}_{2}$ is also indicative of reactions of these species on clean silver, but not clean gold surfaces $[19,27,37,38]$. In sharp contrast, alcohol coupling, aside from methanol self coupling, is not observed on silver, either single crystal silver surfaces [39] or nanoporous silver catalysts [40]. The activation of dioxygen on silver-like sites and the coupling reactions characteristic of gold illustrate the bifunctional nature of the npAu catalyst.

The temperature at which methyl formate, methyl acetate and ethyl acetate evolve in TPRS experiments is substantially higher than was observed on gold single crystals [16]. Calculations of the characteristic pore diffusion times in the nanoporous structure indicate that these higher temperatures observed in TPRS are not due to the effects of diffusion (see Supporting Information). These temperatures are, however, close to the temperature at which methyl formate is formed on single crystal $\operatorname{Ag}(110)$ surfaces. This fact suggests that formation of the coupled products may result from the activation of adsorbed methoxy on silver-like sites, the formaldehyde then reacting with available alkoxy groups to form the coupled products. This issue is under further investigation. Similar arguments apply to the coupling products of 1butanol, except in this case the evolution of butyl butyrate may be desorption-limited, as its temperature of formation is similar to that observed on $\mathrm{Au}(111)$ and is well above the 
temperature expected for formation of butyraldehyde from adsorbed 1-butoxy [16]. These details aside, the TPRS studies demonstrate that atomic $\mathrm{O}$ adsorbed on npAu leads to the cross-coupling of methanol (and alcohols in general) in accord with the mechanism derived from single-crystal Au(111) (Scheme 1) [41]. The activation energies for both methyl formate and methyl acetate estimated from their peak temperatures (assuming first order reactions and a pre-exponential factor of $10^{13} \mathrm{~s}^{-1}$ ) are approximately $20 \mathrm{kcal} / \mathrm{mol}$.

The high concentration of methanol needed to maximize the selectivity for crosscoupling for both the npAu in UHV and in the flow reactor agrees well with previous experiments on $\mathrm{Au}(111)$ conducted under the highly controlled conditions afforded by UHV [16]. Further, the relative surface coverage of the alkoxys under the steady state catalytic conditions for the various alcohol reactant mixtures can be directly determined from the stoichiometry of the coupling reactions for both methanol/ethanol and methanol/1-butanol systems (see Supporting Information) since other reactions channels, such as combustion, are absent (Fig. 8). Similar methods have been applied to calculate the relative coverages of the alkoxy species in the cross-coupling reactions on the $\mathrm{O} / \mathrm{Au}(111)$ surface [16]. It is evident that, for each mole fraction of methanol studied, the surface fraction of methoxy is much less than the methanol mole fraction in the vapor phase. In addition, for the same fraction of methanol of the reactant mixture, the surface methoxy fraction in the methanol/1-butanol system is even smaller than that in the methanol/ethanol case; indicating that the longer-chain adsorbed alkoxy species is are stable on the npAu catalyst surface. This behavior has also been observed on the $\mathrm{O} / \mathrm{Au}(111)$ surface [16] and has been attributed to van der Waals interactions on the basis of density functional theory calculations and is also consistent with the relative gas phase acidities of the alcohols [6]. 


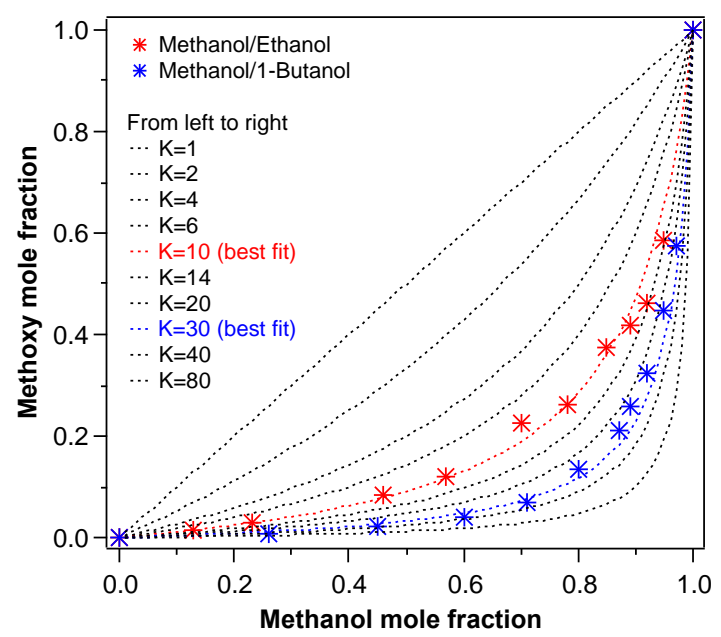

Fig. 8. The fraction of surface methoxy as a function of methanol mole fraction in the alcohol mixtures for both methanol/ethanol and methanol/1-butanol systems. These data were obtained on a npAu ingot. The dashed lines illustrate the methoxy surface concentrations as a function of methanol mole fraction for different equilibrium constants of the displacement reaction between alcohols and surface alkoxys.

The equilibrium constant $\left(K_{e q}\right)$ in Scheme 2 governing the relative concentrations of adsorbed alkoxy species during the steady state reaction was estimated to be $\sim 10$ and $30 \sim 80$ for the methanol/ethanol and methanol/1-butanol systems, respectively (Figs. 8 and S12). These values are somewhat larger than those obtained from model studies on $\mathrm{Au}(111)$ surfaces, where the corresponding equilibrium constants were estimated to be 5 and 10 [16]. In general, however, the results observed with steady-state reactor studies for the coupling selectivity are consistent with the mechanism developed describing the competition of reactions of adsorbed alkoxys species on $\mathrm{Au}(111)$ model surfaces, in which the relative population of the alkoys is determined by an equilibrium between the alcohols in the gas phase and the adsorbed alkoxy species [41] .

Among the cross-coupling products of methanol with ethanol or 1-butanol, the selectivity of methyl esters (methyl acetate or methyl butyrate) is significantly higher than that of formate esters (ethyl formate or butyl formate). This result reflects that the selectivity of ester formation 
is also strongly affected by the relative facility of $\beta-\mathrm{H}$ elimination from the adsorbed alkoxys, which is generally considered to be the rate-limiting step in the oxidation of primary and secondary alcohols [17,18,26,42-45]. In addition, appreciable quantities of methyl formate, resulting from methanol self-coupling, are detected only at a very high methanol fraction in the reactant mixture - above 0.8 methanol for the methanol/ethanol mixtures (Figs. $4 \mathrm{~b}$ and S6b) and above 0.9 methanol for the methanol/1-butanol system (Figs. 5b and S7b) where the methoxy mol fraction starts to exceed $20 \%$.

Based on the equilibrium between the fraction of surface methoxy and gas-phase methanol (Fig. 8), it can be estimated that to achieve an equal initial coverage of adsorbed methoxy and the longer-chain alkoxy (0.50), the methanol fraction in the gas mixture should be $\sim 0.9$ for methanol/ethanol and $\sim 0.97$ for methanol/1-butanol reactions. As such, with a mole fraction of 0.9 methanol in the methanol-ethanol reaction, the relative selectivity to methyl acetate is ca. $75 \%$ and that of methyl formate is ca. $~ 13 \%$ (Fig. $4 \mathrm{~b}$ ). In fact, the total selectivity to acetate products is $87 \%$. Similarly, at 0.97 methanol for the methanol/1-butanol case (methoxy/1-butoxy $\sim 1$ ), the relative selectivities of methyl butyrate and methyl formate formation are $76 \%$ and $24 \%$, respectively, and the total selectivity to butyrate products is $76 \%$ (Fig. 5b). With comparable surface coverage of the respective alkoxys, the preferential formation of methyl acetate or methyl butyrate over methyl formate clearly reflects that the rates of $\beta-\mathrm{H}$ elimination of ethoxy and butoxy are three to five times higher than that of methoxy. Moreover, it was observed that some ethyl formate ester was produced in the methanol/ethanol reaction (see ethyl formate in Fig. S4) but no butyl formate was observed in the methanol/1-butanol reaction. This indicates that the butoxy intermeditate does not exist when formaldehyde of released by $\beta-\mathrm{H}$ elimination from methoxy, whereas some ethoxy does. Thus, $\beta$-H elimination is faster in butoxy 
than in ethoxy. Overall, the rate of $\beta-\mathrm{H}$ elimination observed on the $\mathrm{npAu}$ catalyst follows the order of butoxy > ethoxy > methoxy, in accord with that derived from model studies on $\mathrm{Cu}, \mathrm{Ag}$, and $\mathrm{Au}$ surfaces $[16,26,42,43,45]$.

Further, initially the relative selectivity to form methyl acetate from the methanol/ethanol mixture scales roughly linearly as the methanol mole fraction in the reaction mixture increases; in the meantime, there is a steady decrease in the selectivity for ethyl acetate formation (Fig. 4b and S6). This result indicates that acetaldehyde formed from adsorbed ethoxy preferentially reacts with surface methoxy intermediates, which are not undergoing further $\beta-\mathrm{H}$ elimination to formaldehyde, which would react with ethoxy to yield ethyl formate. This result provides further evidence for the higher rate of $\beta$-H elimination in ethoxy than that in methoxy. Similarly, the rate of $\beta-\mathrm{H}$ elimination in butoxy can be deduced to be higher than that in methoxy on the npAu catalyst.

While it might be expected that the TPRS results obtained on the npAu catalyst could parallel the results observed on model $\mathrm{Au}(111)$ surfaces [16] because of the similarity of the experimental procedures used, the substantial similarity to the dependence of the selectivity on reactant composition observed under ambient pressure conditions to the single crystal work is less expected and quite striking. There are, however, important differences in the product distributions observed in these cases. For example, acetaldehyde was not detected in the methanol-ethanol reaction on the $\mathrm{O} / \mathrm{Au}(111)$ surface [16] or in the UHV studies of the npAu reported here. In addition, $\mathrm{CO}_{2}$ was produced from combustion in both the methanol/ethanol and methanol/1-butanol coupling reactions on both $\mathrm{Au}(111)$ and the npAu ingots studied in UHV, even with a limited initial supply of adsorbed atomic oxygen ( 0.1 monolayer). In contrast, no 
$\mathrm{CO}_{2}$ was produced in the flow reactor, and the formation of aldehyde was observed in the coupling reactions even at very high mole fractions of methanol $(>0.9)$ in the reactant mixture.

These differences are attributed to fundamental differences in the manner in which the TPRS and reactor studies are conducted. In the UHV experiments with either Au single crystal or npAu, oxygen is first deposited on the surface before dosing the gas mixtures of alcohols. Though the initial oxygen coverage is low, it most likely forms oxygen adsorbed both in isolated sites and small regions of 2D oxygen islands; the latter structures are known to form on both $\mathrm{Ag}$ and $\mathrm{Au}$ single crystal surfaces [46-50]. On $\mathrm{Au}(111)$ the $2 \mathrm{D}$ oxide is known to produce combustion $[47,48]$. As a consequence of these locally high oxygen coverages, aldehyde may be readily reacted to form $\mathrm{CO}_{2}$ and water, generally via a formate intermediate $[17,26]$. In the flow reactor, however, the steady-state coverage of oxygen species is very low due to the low probability of oxygen dissociation on npAu surfaces [51] and their exceedingly high reactivity with the alcohol. Adsorbed $\mathrm{O}$, when formed, is rapidly removed by reaction with the alcohol to form the alkoxy species. Even at $\mathrm{O}_{2}$ concentration of $20 \mathrm{vol} . \%$, the oxygen coverage on $\mathrm{npAu}$ catalysts under reaction conditions is apparently too low to afford deeper oxidation or combustion to yield $\mathrm{CO}_{2}$.

The results described here clearly demonstrate that the oxidative cross-coupling of methanol and higher alcohols can be effectively promoted on the npAu catalysts over a wide range of reaction conditions and materials size scale, from UHV to atmospheric pressure and from macroscopic single crystal surfaces to nanoporous alloys. The reaction behaviors, including the product distribution, as observed on the npAu catalysts in both catalytic conditions and controlled studies in UHV closely resemble those observed from the model studies on oxygencovered $\mathrm{Au}(111)$ surface [16]. Most prominently, the factors that have been identified to control 
the product distribution in the cross-coupling reaction of alcohols on single-crystal gold surfaces in UHV are demonstrated to play critical roles in determining the selectivity of various products, especially the esters, on the actual porous gold catalysts at ambient pressure.

\section{CONCLUSIONS}

The vapor phase oxidative cross-coupling of dissimilar alcohols is efficiently promoted on unsupported npAu catalysts under both UHV and ambient pressure conditions using gaseous $\mathrm{O}_{2}$ as an oxidant. Two factors that play critical roles in determining the product distributions, the relative coverage of the alkoxy intermediates and relative facility of $\beta-\mathrm{H}$ elimination, are found to prevail over a wide range of pressure conditions. The relative coverage of the alkoxy species of the parent alcohols, which governs product selectivity, is determined via competition for reaction sites on the catalyst. The optimum selectivity for cross-coupling is achieved at gas phase alcohol compositions far from equal. Prior fundamental studies on single-crystal gold supported by theoretical analysis demonstrate that this competition is governed by weak van der Waal's interactions between the alkyl groups of the alkoxy and the surface. The work reported here clearly establishes the importance of these weak interactions in determining selectivity in heterogeneous catalysis under working conditions.

\section{AUTHOR INFORMATION}

\section{Corresponding Author}

*E-mail: friend@fas.harvard.edu.

\section{Notes}

The authors declare no competing financial interest. 


\section{Acknowledgements}

This work was supported as part of the Integrated Mesoscale Architectures for Sustainable Catalysis, an Energy Frontier Research Center funded by the U.S. Department of Energy, Office of Science, Basic Energy Sciences under Award \# DE-SC0012573. Work at LLNL was performed under the auspices of the U.S. Department of Energy by LLNL under Contract DE-AC5207NA27344.

\section{Appendix A. Supplementary material}

Supplementary data associated with this article can be found, in the online version, at http://dx.doi.org/.

\section{REFERENCES}

[1] G.J. ten Brink, I.W.C.E. Arends, R.A. Sheldon, Science 287 (2000) 1636-1639.

[2] T. Mallat, A. Baiker, Chem. Rev. 104 (2004) 3037-3058.

[3] E. Taarning, K. Egeblad, R. Madsen, C.H. Christensen, Catal. Lett. 116 (2007) 35-40.

[4] C. Marsden, E. Taarning, D. Hansen, L. Johansen, S.K. Klitgaard, K. Egeblad, C. H. Christensen, Green Chem. 10 (2008) 168-170.

[5] M.J. Climent, A. Corma, S. Iborra, Chem. Rev. 111 (2011) 1072-1133.

[6] J.C.F. Rodríguez-Reyes, C.G.F. Siler, W. Liu, A. Tkatchenko, C.M. Friend, R.J. Madix, J. Am. Chem. Soc. 136 (2014) 13333-13340.

[7] D.I. Enache, D.W. Knight, G.J. Hutchings, Catal. Lett. 103 (2005) 43-52.

[8] F.Z. Su, J. Ni, H. Sun, Y. Cao, H.Y. He, K.N. Fan, Chem. Eur. J. 14 (2008) 7131-7135. 
[9] L.C. Wang, Y.M. Liu, M. Chen, Y. Cao, H.Y. He, K.N. Fan, J. Phys. Chem. C 112 (2008) 6981-6987.

[10] A. Wittstock, V. Zielasek, J. Biener, C.M. Friend, M. Bäumer, Science 327 (2010) 319322.

[11] K.M. Kosuda, A. Wittstock, C.M. Friend, M. Bäumer, Angew. Chem. Int. Ed. 51 (2012) $1698-1701$.

[12] M. Estrada, V.V. Costa, S. Beloshapkin, S. Fuentes, E. Stoyanov, E.V. Gusevskaya, A. Simakov, Appl. Catal. A - Gen. 473 (2014) 96-103.

[13] A.S.K. Hashmi, G.J. Hutchings, Angew. Chem. Int. Ed. 45 (2006) 7896-7936.

[14] A.S.K. Hashmi, C. Lothschütz, M. Ackermann, R. Doepp, S. Anantharaman, B. Marchetti, H. Bertagnolli, F. Rominger, Chem. Eur. J. 16 (2010) 8012-8019.

[15] M.L. Personick, B. Zugic, M.M. Biener, J. Biener, R.J. Madix, C.M. Friend, submitted.

[16] B. Xu, R.J. Madix, C.M. Friend, J. Am. Chem. Soc. 132 (2010) 16571-16580.

[17] B. Xu, X. Liu, J. Haubrich, R.J. Madix, C.M. Friend, Angew. Chem. Int. Ed. 48 (2009) 4206-4209.

[18] X. Liu, B. Xu, J. Haubrich, R.J. Madix, C.M. Friend, J. Am. Chem. Soc. 131 (2009) $5757-5759$.

[19] D.A. Outka, R.J. Madix, J. Am. Chem. Soc. 109 (1987) 1708-1714.

[20] B. Xu, J. Haubrich, C.G. Freyschlag, R.J. Madix, C.M. Friend, Chem. Sci. 1 (2010) $310-314$.

[21] K.J. Stowers, R.J. Madix, C.M. Friend, J. Catal. 308 (2013) 131-141.

[22] A. Schaefer, D. Ragazzon, A. Wittstock, L.E. Walle, A. Borg, M. Bäumer, A. Sandell, J. Phys. Chem. C. 116 (2012) 4564-4571. 
[23] X. Deng, B.K. Min, A. Guloy, C.M. Friend J. Am. Chem. Soc. 127 (2005) 9267-9270.

[24] B.K. Min, A.R. Alemozafar, D Pinnaduwage, A.X Deng, C.M. Friend, J. Phys. Chem. B 110 (2006) 19833-19838.

[25] S. Röhe, K. Frank, A. Schaefer, A. Wittstock, V. Zielasek, A. Rosenauer, M. Bäumer, Surf. Sci. 609 (2013) 106-112.

[26] I.E. Wachs, R.J. Madix, Surf. Sci. 76 (1978) 531-558.

[27] B.A. Sexton, R.J. Madix, Surf. Sci. 105 (1981) 177-195.

[28] L.C. Wang, K.J. Stowers, B. Zugic, M.M. Biener, J. Biener, C.M. Friend, R.J. Madix, Catal. Sci. Technol. 5 (2015) 1299-1306.

[29] Y. Guan, E. Hensen, Appl. Catal. A - Gen. 361 (2009) 49-56.

[30] L.V. Moskaleva, S. Röhe, A. Wittstock, V. Zielasek, T. Klüner, K.M. Neyman, M. Bäumer, Phys. Chem. Chem. Phys. 13 (2011) 4529-4539.

[31] A. Wittstock, B. Neumann, A. Schaefer, K. Dumbuya, C. Kübel, M.M. Biener, V. Zielasek, H.P. Steinrück, J.M. Gottfried, J. Biener, A. Hamza, M. Bäumer, J. Phys. Chem. C. 113 (2009) 5593-5600.

[32] L.C. Wang, Y. Zhong, D. Widmann, J. Weissmueller, R.J. Behm, ChemCatChem 4 (2012) 251-259.

[33] J.L.C. Fajín, M.N.D.S. Cordeiro, J.R.B. Gomes, Chem. Commun. 47 (2011) 8403-8405.

[34] C.T. Campbell, Surf. Sci. 157 (1985) 43-60.

[35] M.A. Barteau, R.J. Madix, Surf. Sci. 97 (1980) 101-110.

[36] B. Xu, C.G.F. Siler, R.J. Madix, C.M. Friend, Chem. Eur. J. 20 (2014) 4646-4652.

[37] D.A. Outka, R.J. Madix, Surf. Sci. 179 (1987) 361-376.

[38] W.Y. Yu, G.M. Mullen, D.W. Flaherty, C.B. Mullins, J. Am. Chem. Soc. 136 (2014) 
[39] C.G.F. Siler, Ph.D. Thesis, Harvard University, Department of Chemistry and Chemical Biology, 2014.

[40] Z. Li, J. Xu, X. Gu, K. Wang, W. Wang, X. Zhang, Z. Zhang, Y. Ding, ChemCatChem. 5 (2013) 1705-1708.

[41] B. Xu, X. Liu, J. Haubrich, C.M. Friend, Nature Chem. 2 (2009) 61-65.

[42] Q. Dai, A.J. Gellman, Surf. Sci. 257 (1991) 103-112.

[43] J.G. Forbes, A.J. Gellman, J. Am. Chem. Soc. 115 (1993) 6277-6283.

[44] I.E. Wachs, R.J. Madix, Appl. Surf. Sci. 1 (1978) 303-328.

[45] I.E. Wachs, R.J. Madix, J. Catal. 53 (1978) 208-227.

[46] B.K. Min, X. Deng, D. Pinnaduwage, R. Schalek, C.M. Friend, Physical Review B. 72 (2005) 121410-121410.

[47] T.A. Baker, C.M. Friend, E. Kaxiras, J. Phys. Chem. C. 113 (2009) 3232-3238.

[48] T.A. Baker, B. Xu, X. Liu, E. Kaxiras, C.M. Friend, J. Phys. Chem. C, 113 (2009) $16561-16564$.

[49] J. Schnadt, J. Knudsen, X.L. Hu, A. Michaelides, R.T. Vang, Phys. Rev. B 80 (2009) 075424.

[50] T. Hashizume, M. Taniguchi, K. Motai, H. Lu, K. Tanaka, T. Sakurai, Surf. Sci. 266 (1992) 282-284.

[51] L.C. Wang, H.J. Jin, D. Widmann, J. Weissmüller, R.J. Behm, J. Catal. 278 (2011) 219227. 
Graphical abstract

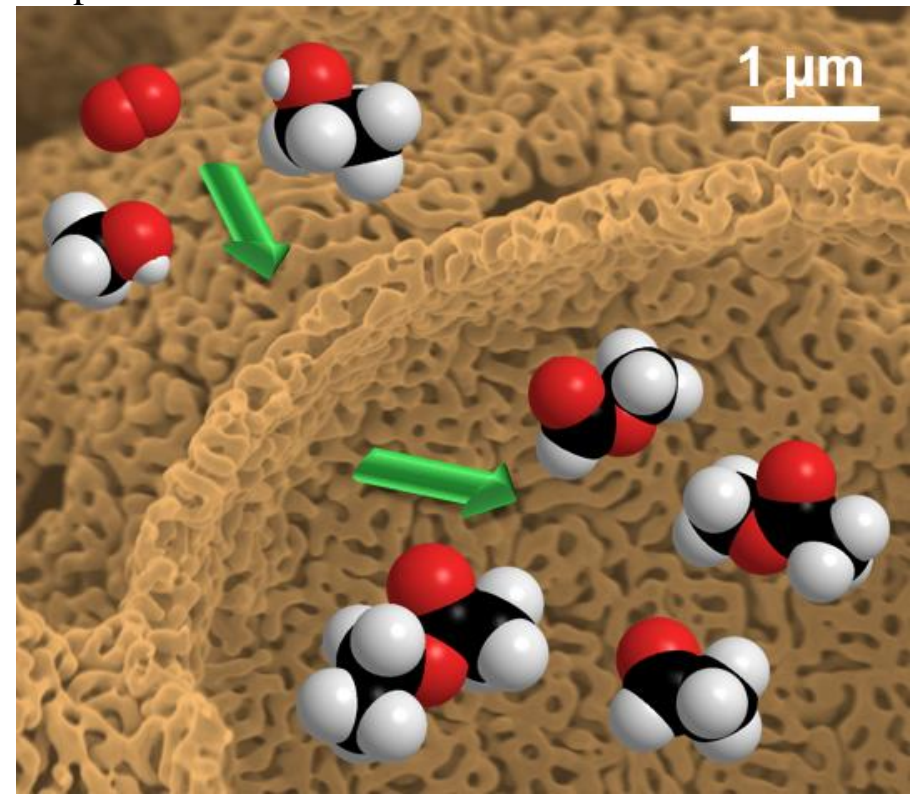

